\title{
Torque-Angle-Based Direct Torque Control for Interior Permanent-Magnet Synchronous Motor Drivers in Electric Vehicles
}

\author{
Xin Qiu ${ }^{\dagger}$, Wenxin Huang ${ }^{*}$, and Feifei Bu* \\ $\dot{\dagger}^{*}$ Jiangsu Key Laboratory of New Energy Generation and Power Conversion, Nanjing University of Aeronautics and \\ Astronautics, Nanjing, China
}

\begin{abstract}
A modified direct torque control (DTC) method based on torque angle is proposed for interior permanent-magnet synchronous motor (IPMSM) drivers used in electric vehicles (EVs). Given the close relationship between torque and torque angle, proper voltage vectors are selected by the proposed DTC method to change the torque angle rapidly and regulate the torque quickly. The amplitude and angle of the voltage vectors are determined by the torque loop and stator flux-linkage loop, respectively, with the help of the position of the stator flux linkage. Furthermore, to satisfy the torque performance request of EVs, the nonlinear dead-time of the invertor caused by parasitic capacitances is considered and compensated to improve steady torque performance. The stable operation region of the IPMSM DTC driver for voltage and current limits is investigated for reliability. The experimental results prove that the proposed DTC has good torque performance with a brief control structure.
\end{abstract}

Key words: Dead-time compensation, Direct torque control, Interior permanent-magnet synchronous motor, Torque accuracy, Torque angle

\section{INTRODUCTION}

Permanent-magnet synchronous motors (PMSMs), which have high efficiency and large torque-to-volume ratio, are widely used in electric vehicles (EVs), particularly in battery-powered EVs [1]-[4]. PMSMs are classified into interior PMSMs (IPMSMs) and surface-mounted PMSMs (SPMSMs) according to the rotor structure. IPMSMs usually have better field-weakening performance and larger torque-to-current ratios than SPMSMs because of the narrower equivalent air gap and additional reluctance torque of the former [5]-[7]. Therefore, IPMSMs are more suitable for EV drive systems than SPMSMs. Despite these merits, IPMSMs have inductance parameters that change nonlinearly with different load currents, which is disadvantageous for the control [8]-[10].

High-performance control strategies for IPMSMs mainly

Manuscript received May 2 2013; Revised Aug. 12013

Recommended for publication by the associate editor Sanjeet K. Dwivedi. †Corresponding Author: qiuxin@nuaa.edu.cn

Tel: +86-138-5167-9062, Nanjing Univ. of Aeronautics and Astronautics

*Jiangsu Key Laboratory of New Energy Generation and Power Conversion, Nanjing University of Aeronautics and Astronautics, China include field-oriented control (FOC) and direct torque control (DTC) [11]-[29]. FOC simplifies the IPMSM into equivalent DC motors by coordinate transformation and uses quadrature and direct axis currents as control objects. However, the torque-to-current ratio of an IPMSM changes with varying inductance parameters, thus significantly affecting torque performance. To overcome this problem, inductance identification, which usually requires offline tests or complicated online calculations, is necessary [21], [22].

Compared with the FOC, the DTC uses torque and stator flux as direct control objects and possesses several advantages such as low parameter dependence, needlessness of a position sensor, and fast dynamic response [17], [18]. However, the hysteresis controllers and basic switching tables used in conventional DTC create disadvantages such as variable switching frequency, large torque, and flux ripples [17]. Numerous improved DTC schemes, which can mainly be divided into switching-table-based DTC schemes and space vector pulse-width modulation (SVPWM)-based DTC schemes, have been proposed in recent years to overcome the aforementioned disadvantages [15]-[29] according to the approach of implementing voltage vectors.

In switching-table-based DTC schemes, the subdivision of 
the switching table effectively reduces torque and flux ripples [15], [16]. In [16], 1 sampling period is subdivided into 2 equal time intervals, thus generating an accurate switching table with 12 voltage vectors is generated. Multilevel inverters can also provide more voltage vectors [23]. Voltage vector duration regulation, which introduces zero voltage vectors, is another effective approach [24]. Predictive control [25] and fuzzy logic [26] can also be introduced to optimize the voltage duration. These methods obtain excellent effects as expected. However, these methods are usually based on hysteresis controllers or require complex calculations and hardware support.

Arbitrary voltage vectors in linear modulation areas can be obtained by the SVPWM in fixed switching frequency. Based on the SVPWM, DTC implementation focuses on the regulation of output voltage vectors with torque and flux errors, and a multitude of schemes are proposed in literature [16], [18], [27]-[29]. A SVPWM DTC scheme with closed-loop torque control is reported [18]. The SVPWM DTC scheme involves the calculation of output voltage vectors by the error between the reference flux vector and actual flux vector. A scheme based on torque angle increment is introduced in [27]. In these methods, output voltage vectors are usually obtained by a series of calculations on flux linkage and speed, thus weakening the direct specialty of DTC relatively. Most SVPWM DTC schemes are implanted in cartesian coordinate systems; nevertheless, the SVPWM DTC scheme can also operate in polar coordinate systems. A simple DTC method that uses vectors with variable amplitudes and angles is proposed in [29]. However, this method relies on the weighting factor and regulates torque by proportional control.

In a speed regulating system, the output torque follows the load torque naturally because of the adjustment of the speed loop. However, the EV drive system mainly operates in torque-control mode and the speed functions only in an auxiliary role. Therefore, torque performance, including steady-state response and dynamic response, is important for the EV drive system [11], [30]. Although a DTC scheme has good robustness, factors such as inverter dead-time and flux observer can still affect the system, particularly at low speeds [14], [19]. Literature on dead time is mainly focused on the improvement of current waveforms [31], whereas factors that affect torque performance and EV application are rarely reported.

This paper proposes an improved DTC scheme based on torque angle for the EV IPMSM drive systems. The proposed DTC scheme regulates torque by quickly changing the torque angle with appropriate voltage vectors. The final output voltage vectors are obtained in the form of amplitude and angle, which are directly determined by the torque. Flux-linkage PI controllers only require the position of the stator flux. Therefore, the proposed DTC scheme retains the simplicity and robustness of conventional DTC. The affecting factors of torque performance in DTC are investigated for contenting the
EV drive application. By using a nonlinear dead-time compensation that considers parasitic capacitances, the torque accuracy and steady torque performance is improved significantly. Furthermore, the stable operation region of DTC that considers voltage, as well as the current limits of both the motor and invertor, is discussed for safe operation. Detailed experimental results confirm the effectiveness of the proposed DTC scheme.

\section{IPMSM EQUATIONS}

Based on previous studies [16]-[20], the model of an IPMSM in the rotor reference frame can be expressed as follows:

$$
\begin{gathered}
\left\{\begin{array}{l}
\psi_{d}=\psi_{f}+L_{d} i_{d} \\
\psi_{q}=L_{q} i_{q} \\
\psi_{s}=\sqrt{\psi_{d}^{2}+\psi_{q}^{2}}
\end{array}\right. \\
\left\{\begin{array}{l}
u_{d}=R_{s} i_{d}+p \psi_{d}-\omega \psi_{q} \\
u_{q}=R_{s} i_{q}+p \psi_{q}+\omega \psi_{d}
\end{array},\right. \\
T_{e}=\frac{3}{2} P\left(\psi_{d} i_{q}-\psi_{q} i_{d}\right)
\end{gathered}
$$

In the stationary stator reference frame, the model of an IPMSM is given by the following:

$$
\left\{\begin{array}{l}
\psi_{\alpha}=\int\left(u_{\alpha}-R_{s} i_{\alpha}\right) d t \\
\psi_{\beta}=\int\left(u_{\beta}-R_{s} i_{\beta}\right) d t, \\
\psi_{s}=\sqrt{\psi_{\alpha}^{2}+\psi_{\beta}^{2}} \\
T_{e}=\frac{3}{2} P\left(\psi_{\alpha} i_{\beta}-\psi_{\beta} i_{\alpha}\right) .
\end{array}\right.
$$

Equation (3) can be expanded with stator and rotor flux linkages as follows:

$$
T_{e}=\frac{3 P \psi_{s}}{4 L_{d} L_{q}}\left[2 \psi_{f} L_{q} \sin \delta+\psi_{s}\left(L_{d}-L_{q}\right) \sin 2 \delta\right] .
$$

in Equations (1) to (6),

$u_{d}, u_{q}: \quad$ stator voltage on $d$ and $q$ axes;

$i_{d}, i_{q}$ : $\quad$ stator current on $d$ and $q$ axes;

$L_{d}, L_{q}: \quad$ direct and quadrature inductances;

$\psi_{d}, \psi_{q}$ : amplitudes of stator flux linkages on $d$ and $q$ axes;

$u_{\alpha}, u_{\beta}: \quad$ stator voltage on $\alpha$ and $\beta$ axes;

$i_{\alpha}, i_{\beta}$ : $\quad$ stator current on $\alpha$ and $\beta$ axes;

$\psi_{\alpha}, \psi_{\beta}$ : amplitudes of stator flux linkages on $\alpha$ and $\beta$ axes;

$\psi_{s}, \psi_{f}: \quad$ amplitudes of stator and rotor flux linkages;

$R_{s}: \quad$ stator resistance;

$p: \quad$ differential operator;

$\omega: \quad$ rotor electrical speed in $\mathrm{rad} / \mathrm{s}$;

$P$ : number of pole pairs;

$\delta$ : $\quad$ torque angle, electrical angle between stator and 


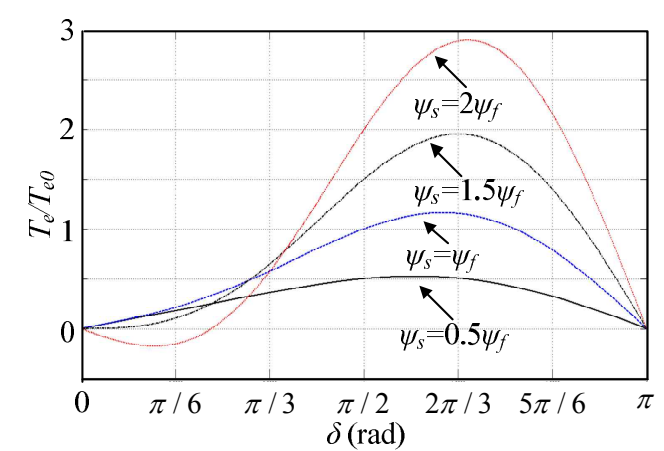

Fig. 1. Torque characteristic of IPMSM with different stator flux linkage $\psi_{s}$.

rotor flux linkages.

To simplify the analysis, the symmetrically negative torque zone $\delta<0$ is not discussed. Equation (6) can then be graphed with Fig. 1:

$$
T_{e 0}=\frac{3 P \psi_{s} \psi_{f}}{2 L_{d}} .
$$

Fig. 1 shows that an increase in torque is not monotonic if the stator flux is not suitable. Therefore, investigating the stable operation region of IPMSM is necessary.

\section{STABLE OPERATION REGION WITH DTC SCHEME}

In IPMSM DTC schemes, the torque and stator flux linkage are usually the direct control-variables. Hence, the stable operation region should be limited by maximal torque (or torque angle) and stator flux linkage.

A peak torque is inherent with increasing $\delta$ and a nadir appears with increasing $\psi_{s}$ (Fig. 1). The nadir is forbidden because it destroys the control monotonicity. To ensure that IPMSMs work in a monotonic region, two prerequisites must be satisfied [18]:

$$
\left\{\begin{array}{l}
\frac{d T_{e}}{d \delta}>0 \Rightarrow \delta<\arccos \left[\frac{\frac{L_{q}}{L_{q}-L_{d}}+\sqrt{\left(\frac{L_{q}}{L_{q}-L_{d}}\right)^{2}+8}}{4}\right] \\
\left.\frac{d T_{e}}{d \psi_{s}}\right|_{\delta=0}>0 \Rightarrow \psi_{s}<\frac{L_{q}}{L_{q}-L_{d}} \psi_{f}
\end{array} .\right.
$$

However, Equation (8) focuses only on the torque, and the current and voltage limits are not considered. To ensure the safe operation of inverters and IPMSMs in EVs, the voltage and current limits $\left(U_{\max }, I_{\max }\right)$ need to be involved.

$$
\left\{\begin{array}{l}
I_{d}^{2}+I_{q}^{2} \leq I_{\max }^{2} \Rightarrow\left(\frac{\psi_{d}-\psi_{f}}{L_{d}}\right)^{2}+\left(\frac{\psi_{q}}{L_{q}}\right)^{2} \leq I_{\max }^{2} \\
\omega \psi_{s} \leq U_{\max } \Rightarrow \omega \sqrt{\psi_{d}^{2}+\psi_{q}^{2}} \leq U_{\max }
\end{array} .\right.
$$

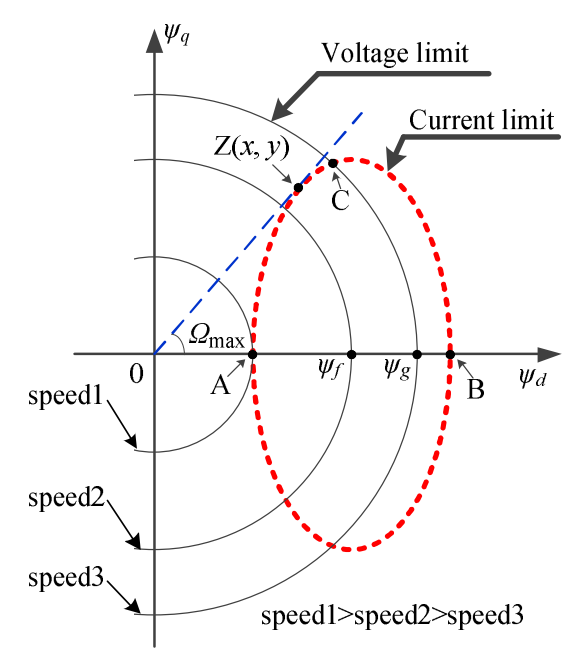

Fig. 2. Voltage and current limits for safe operation in DTC.

Equation (9) can be graphically represented by Fig. 2, in which Point A $\left(\psi_{f}-I_{\max } L_{d}, 0\right)$ and Point B $\left(\psi_{f}+I_{\max } L_{d}, 0\right)$ denote the maximum flux weakening and flux-increasing capacities, respectively. An IPMSM is usually designed with $\psi_{f}>I_{\max } L_{d}$ to avoid irreversible demagnetization; therefore, the torque angle cannot exceed $90^{\circ}$ in geometrical terms and should satisfy the requirement in Equation (8).

\section{A. Torque and Torque Angle Limitation}

Fig. 2 shows that the maximal torque angle is determined by the intersection (Point $\mathrm{C}$ ) of the current-limit ellipse and given stator flux $\left(\psi_{g}\right)$ round:

$$
\left\{\begin{array}{l}
\left(\frac{\psi_{d}-\psi_{f}}{L_{d}}\right)^{2}+\left(\frac{\psi_{q}}{L_{q}}\right)^{2}=I_{\max }^{2} \\
\sqrt{\psi_{d}^{2}+\psi_{q}^{2}}=\psi_{g} \\
\psi_{d}=\psi_{g} \cos \left(\delta_{\max }\right) \\
\psi_{q}=\psi_{g} \sin \left(\delta_{\max }\right)
\end{array} .\right.
$$

From Equation (10), the maximal torque angle is as follows:

$$
\delta_{\max }=\arccos \frac{\psi_{f} L_{q}^{2}-L_{d} \sqrt{\alpha}}{\psi_{g}\left(L_{q}^{2}-L_{d}^{2}\right)}
$$

where

$$
\alpha=I_{\max }^{2} L_{q}^{4}+\psi_{f}^{2} L_{q}^{2}+\psi_{g}^{2} L_{d}^{2}-\psi_{g}^{2} L_{q}^{2}-I_{\max }^{2} L_{d}^{2} L_{q}^{2} .
$$

By substituting Equation (11) into Equation (6), the torque limitation is obtained. However, the equation of the maximal torque is cumbersome and is described expediently with $\delta_{\max }$ (Equation (13)).

$$
\max \left(T_{e}\right)=\frac{3 P \psi_{s}}{4 L_{d} L_{q}}\left[2 \psi_{f} L_{q} \sin \delta_{\text {max }}+\psi_{s}\left(L_{d}-L_{q}\right) \sin 2 \delta_{\text {max }}\right]
$$

The maximal torque angle in Equation (11) is determined 
by both $\psi_{g}$ and $I_{\max }$. The maximal torque angle $\Omega_{\max }$ with arbitrary $\psi_{g}$ can be determined by the tangent from the original point to the current-limit ellipse (Fig. 2). The point of tangency $\mathrm{Z}(x, y)$ can be expressed as follows:

$$
\left\{\begin{array}{l}
x=\frac{\psi_{f}^{2}-I_{\max }^{2} L_{d}^{2}}{\psi_{f}} \\
y=\frac{L_{q} I_{\max } \sqrt{\psi_{f}^{2}-I_{\max }^{2} L_{d}^{2}}}{\psi_{f}}
\end{array} .\right.
$$

$\Omega_{\max }$ is expressed as follows:

$$
\Omega_{\max }=\arctan \left(\frac{y}{x}\right)=\arctan \frac{L_{q} I_{\text {max }}}{\sqrt{\psi_{f}^{2}-I_{\text {max }}^{2} L_{d}^{2}}} .
$$

The stator flux linkage of Point $\mathrm{Z}$ is as follows:

$$
\psi_{Z}=\frac{\sqrt{\left(\psi_{f}^{2}-I_{\max }^{2} L_{d}^{2}\right)\left(\psi_{f}^{2}-I_{\max }^{2} L_{d}^{2}+I_{\max }^{2} L_{q}^{2}\right)}}{\psi_{f}} .
$$

\section{B. Stator Flux-Linkage Limitation}

Similarly, the best stator flux linkage to obtain the largest torque can be given by the following:

$$
\frac{d T_{e}}{d \psi_{s}}=0 \Rightarrow \psi_{s}=\frac{\psi_{f} L_{q}}{2\left(L_{q}-L_{d}\right) \cos \delta} .
$$

According to the premise of Equation (8), a large flux linkage is better because $\delta$ increase from Equation (17). Nevertheless, the optimum operating point of an IPMSM is designed near the inflexions of the magnetization curves to achieve the least wastage of ferromagnetic materials. Moreover, a large flux linkage can result in saturation. Therefore, $\psi_{g}$ is usually given nearby $\psi_{f}$ in the constant torque region.

In the constant power region, $\psi_{g}$ should satisfy the demand of Equation (9):

$$
\psi_{g} \leq \frac{U_{\max }}{\omega}=\frac{U_{d c}}{\sqrt{3} \omega} .
$$

where $U_{d c}$ is the bus voltage. To ensure the regulation of output torque, a considerable amount of voltage margin is necessary.

The abovementioned limitation of torque (angle) and stator flux linkage can restrict the IPMSM work within the voltage and current limits from the point of DTC, which is helpful in terms of the reliability requirements of EV drive systems.

\section{PROPOSED DTC SCHEME}

The aforementioned analysis shows that a monotonic relationship exists between torque and torque angle under appropriate conditions. Thus, the control of the torque angle is equivalent to the control of the torque.

The equation of stator flux linkage expressed in the stationary frame is as follows:

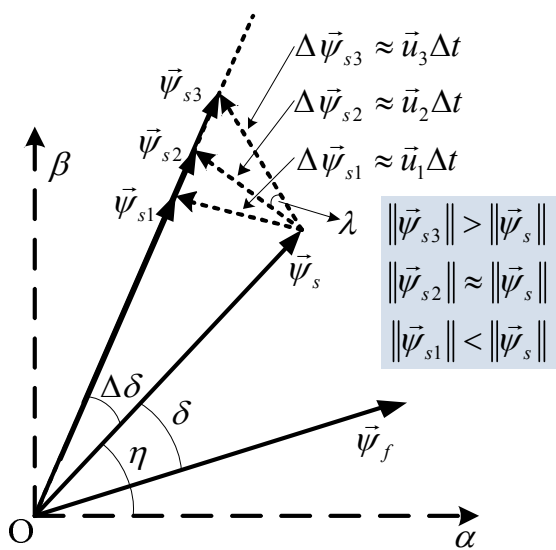

Fig. 3. Variation of the stator flux linkage in one control period.

$$
\psi_{s}=\int e_{s} d t=\int\left(u_{s}-R_{s} i_{s}\right) d t .
$$

where $e_{s}$ is the stator back EMF, and $u_{s}$ and $i_{s}$ are the stator voltage and current, respectively. The variation of the stator flux linkage in one control period $\Delta t$ is shown in Fig. 3. The stator flux linkage has three possible states with different voltage vectors:

$$
\left\{\begin{array}{l}
\vec{\psi}_{s 1}=\vec{\psi}_{s}+\Delta \vec{\psi}_{s 1} \\
\vec{\psi}_{s 2}=\vec{\psi}_{s}+\Delta \vec{\psi}_{s 2} \\
\vec{\psi}_{s 3}=\vec{\psi}_{s}+\Delta \vec{\psi}_{s 3}
\end{array} .\right.
$$

In the analysis, the effect of $R_{s}$ is neglected. $\vec{\psi}_{f}$ can be considered motionless in the transient analysis because the rotor inertia time constant is significantly smaller than the electrical time constant.

From Equation (20) and Fig. 3, an efficient and quick approach to changing the torque angle is the regulation of the amplitude of voltage vector in the vertical direction of the stator flux linkage, similar to the application of voltage vector $\vec{u}_{2}$. The amplitude of the stator flux linkage is constant because $\Delta \delta$ in one control period is very small.

$$
\left\|\vec{\psi}_{s 2}\right\|=\left\|\vec{\psi}_{s}\right\| / \cos (\Delta \delta) \approx\left\|\vec{\psi}_{s}\right\| .
$$

The amplitude of stator flux linkage can be regulated by altering the direction of the voltage vector. $\left\|\vec{\psi}_{s 3}\right\|>\left\|\vec{\psi}_{s}\right\|$, and $\left\|\vec{\psi}_{s 1}\right\|<\left\|\vec{\psi}_{s}\right\|$ (Fig. 3). By using the same principle applied in Equation (21), the effect of the direction of the voltage vector on torque angle is negligible if the angle $\lambda$ is small.

Consequently, little interaction effect is observed between the torque angle and amplitude of the stator flux linkage, which can be controlled directly by regulating the amplitude and angle of the voltage vector, respectively.

According to the above analysis, a torque-angle-based DTC scheme is obtained. The block diagram of this scheme is shown in Fig. 4. In the proposed scheme, the amplitude and angle of the output voltage vector are regulated directly by the torque and stator flux linkage errors with PI regulators, 


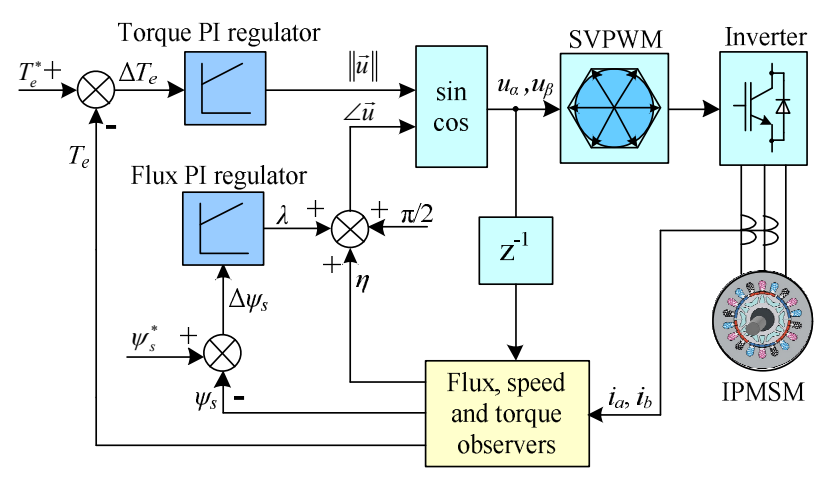

Fig. 4. Block diagram of the proposed DTC scheme.

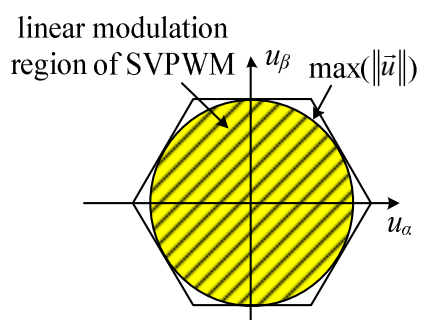

Fig. 5. Modulation region of the voltage vector.

respectively. The output voltage vector is synthesized by the SVPWM.

\section{A. Amplitude Regulation of Output Voltage Vector}

$T_{e}^{*}$ is the given torque, which is given by the upper computer in the EV drive system (Fig. 4). The amplitude of the output voltage vector is regulated by a torque PI regulator in a discrete form:

$$
\|\vec{u}(k)\|=K_{p}\left(T_{e}^{*}(k)-T_{e}(k)\right)+K_{i} \sum T_{s}\left(T_{e}^{*}(k)-T_{e}(k)\right) .
$$

where $K_{p}$ and $K_{i}$ are the proportional and integral parameters, respectively, and $T_{s}$ is the sampling time of the discrete system. The amplitude of the output voltage vector is limited between zero and $U_{d c} / \sqrt{3}$.

The amplitude regulation of the output voltage vector is necessary to limit the voltage vector in the linear modulation region of SVPWM (Fig. 5).

\section{B. Angle Regulation of Output Voltage Vector}

$\psi_{s}^{*}$ is the given amplitude of the stator flux linkage. The angle change of the output voltage vector is obtained by the flux-linkage PI regulator and is expressed as follows:

$$
\lambda(k)=K_{p}\left(\psi_{s}^{*}(k)-\psi_{s}(k)\right)+K_{i} \sum T_{s}\left(\psi_{s}^{*}(k)-\psi_{s}(k)\right) .
$$

The angle of output voltage vector is given by the following:

$$
\angle \vec{u}(k)=\lambda(k)+\eta(k)+\pi / 2,
$$

where $\eta$ is the angle of flux linkage in real time. $\lambda$ is limited within $\pm 5^{\circ}$ by experiments because a larger $\lambda$ produces more torque ripples.
The $K_{p}$ and $K_{i}$ used in Equations (22) and (23) are usually turned to be compromised between the steady and dynamic performances. Given the little interaction effect between the regulations of the torque and the stator flux linkage, the two PI parameters can be adjusted independently.

Upon obtaining the amplitude and angle of the voltage vector, voltage components $u_{\alpha}$ and $u_{\beta}$ for SVPWM are calculated simply with the trigonometric transformation.

$$
\left\{\begin{array}{l}
u_{\alpha}(k)=\|\vec{u}(k)\| \cos (\angle \vec{u}(k)) \\
u_{\beta}(k)=\|\vec{u}(k)\| \sin (\angle \vec{u}(k))
\end{array} .\right.
$$

\section{Stator Flux-Linkage Estimation}

Stator flux linkage is a key variable of DTC, particularly in low speeds. The estimation of stator flux linkage in low speeds has been investigated deeply in various studies such as [14], [19], and [28]. However, the improvement of stator flux-linkage estimation is not the emphasis of this paper. Consequently, the current model in Equation (1) is employed to obtain the stator flux linkage in zero and low speeds [28]. A conventional low-pass filter (LPF) with a variable cut-off frequency and compensations for amplitude and angle is employed to obtain the stator flux linkage in moderate and high speeds [29].

$$
\left\{\begin{array}{l}
\psi_{\alpha}(s)=G(s) e_{\alpha}(s)=\frac{1}{s+\omega_{c}} e_{\alpha}(s) \\
\psi_{\beta}(s)=G(s) e_{\beta}(s)=\frac{1}{s+\omega_{c}} e_{\beta}(s)
\end{array} .\right.
$$

where $e_{\alpha}$ and $e_{\beta}$ is the stator back EMF on $\alpha$ and $\beta$ axes, respectively; $\omega_{c}$ is the cut-off frequency; $\omega_{c}=\rho \omega$. A constant $\rho$ is usually selected between 0.1 and 0.5 . The amplitude and angle errors caused by LPF are constant and are expressed as follows:

$$
\left\{\begin{array}{l}
\varepsilon_{\text {amp }}=\frac{\sqrt{\omega^{2}+\omega_{c}^{2}}}{\omega}=\sqrt{1+\rho^{2}} \\
\varepsilon_{\text {ang }}=-\operatorname{atan} \frac{\omega_{c}}{\omega}=-\operatorname{atan} \rho
\end{array} .\right.
$$

The $\eta$ in Equation (24) is calculated by the following:

$$
\eta=\arctan \left(\psi_{\beta} / \psi_{\alpha}\right) \text {. }
$$

The amplitude and angle of flux linkage calculated by Equations (4) and (28) must be revised by multiplying $\varepsilon_{a m p}$ and adding $\varepsilon_{\text {arg }}$.

\section{FACTORS THAT INFLUENCE TORQUE PERFORMANCE}

The general motion equation of a motor is expressed as follows:

$$
T_{e}-T_{l}=J \frac{d \omega_{m}}{d t} .
$$

where $T_{l}$ is the load torque, $J$ is the motor rotary inertia, and $\omega_{m}$ is the rotor mechanical speed. If the motor operates in 
speed-control mode, $d \omega_{m}=0$ when speed is stable; thus, $T_{e}=$ $T_{l}$. However, if the motor operates in torque-control mode, no equilibrium exists in the relationship between $T_{e}$ and $T_{l}$ and system performance relies mainly on the torque-control ability.

An EV usually operates in torque-control mode to match the driving habit of a conventional vehicle. Therefore, torque performance is important for the EV drive system. Numerous studies have proven that DTC has a good steady-state response, dynamic response, and robustness. However, torque accuracy has rarely been considered in previous studies.

In the torque closed-loop control system, torque accuracy depends on feedback torque, which is usually calculated by Equation (5) in DTC schemes. The accuracy of stator flux has a significant effect on feedback torque and is related to computational data and computing method. The method of flux calculation has been discussed in Section IV. However, the values for integration in Equation (4) require revision.

The values for integration in Equation (4) include $u_{\alpha}, i_{\alpha}, u_{\beta}$, $i_{\beta}$, and $R_{s}$. Currents are usually measured by sensors in the IPMSM drive system. The value of stator resistance $R_{s}$ changes with coil temperature, which can be estimated by temperature measurements with thermocouple. Nevertheless, losses on voltages caused by the inverter are difficult to measure and mainly result from the dead time and forward voltage drop of switches. Although forward voltage drop is relatively constant, the influence of dead time varies with different motor speeds and currents.

To prevent the straight-through problem of the bridge arm, the dead time must be inserted in the drive signals of the upper and lower switches [31]. The dead-time effect in an ideal condition is shown in Fig. 6. Given the diode freewheeling, the actual output voltage lasts $\left(T_{\text {give }}-T_{d}\right)$ if the phase current flows out of the midpoint of the bridge $\left(i_{p}>0\right)$; however, the actual output voltage lasts $\left(T_{\text {give }}+T_{d}\right)$ if the phase current $i_{p}>0$. For this reason, the actual output voltage is diverged from the given voltage, thus causing the actual voltage in the motor to differ from the expected voltage.

The analysis of dead time mentioned above is conducted in the ideal condition. However, in actual circuits, the inherent parasitic-capacitances of power switches and additional snubber circuits are usually observed, thus destroying the ideal status of dead time (Fig. 7). By taking the condition of $i_{p}>0$ as an example, when $S_{1}$ is $\mathrm{ON}$ and $S_{2}$ is OFF, the equivalent capacitance $C_{2}$ begins to charge (the forward voltage drop is ignored); when $S_{1}$ and $S_{2}$ are OFF, the electrical charges stored in $C_{2}$ and $C_{I}$ must be charged before the freewheeling of diode $D_{2}$. During this time, the midpoint voltage is clamped to $U_{d c}$; therefore, the actual dead time is shorter than the ideal dead time. The same situation also exists in the condition of $i_{p}<0$, but the actual dead time is longer than the ideal dead time.

The time difference is mainly determined by the equivalent

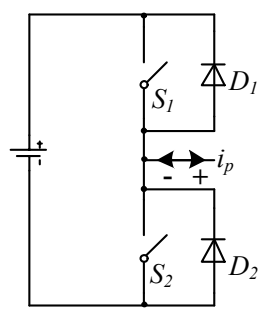

(a)

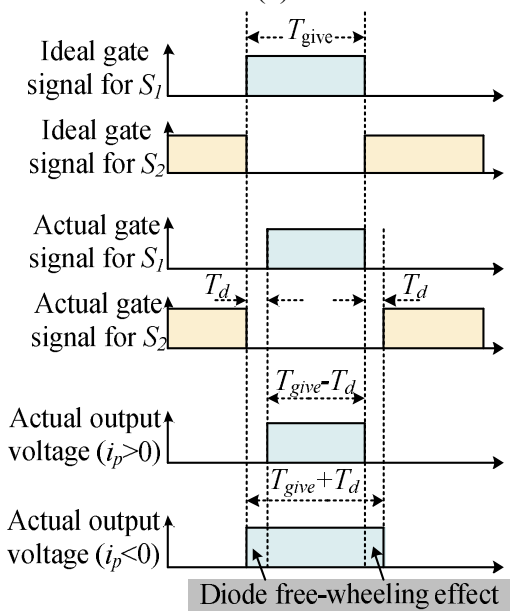

(b)

Fig. 6. Dead time of the inverter: (a) ideal bridge arm and (b) actual output voltage affected by diode freewheeling.

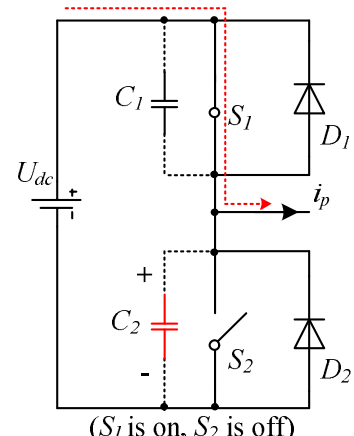

$\left(S_{1}\right.$ is on, $S_{2}$ is off)

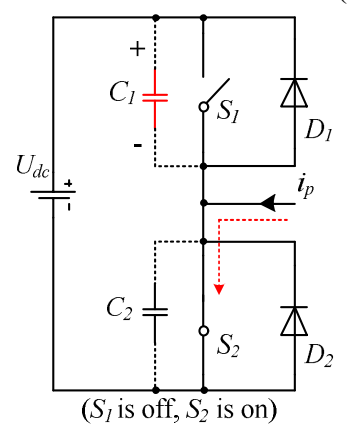

(b)

Fig. 7. Effect of parasitic capacitance of the switch on the ON time and OFF time: (a) $i_{p}>0$ and (b) $i_{p}<0$. 


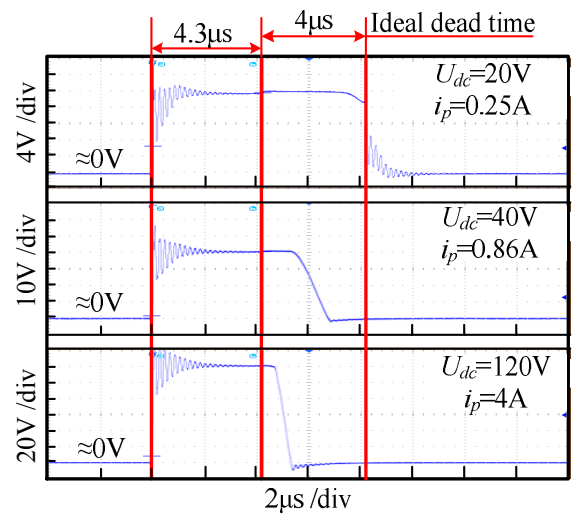

Fig. 8. Waveforms of midpoint voltage with different phase currents.

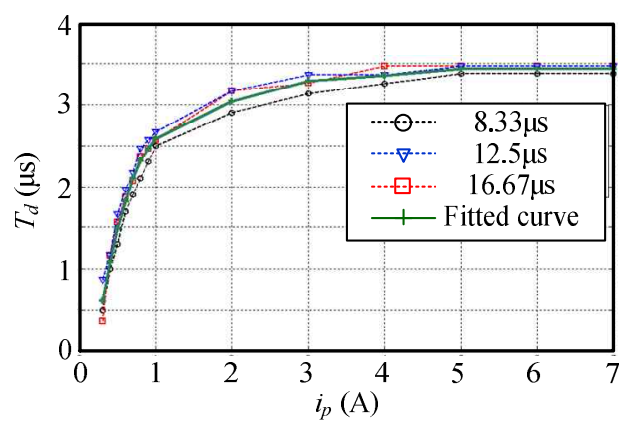

Fig. 9. Dead times with different phase currents and given switch-on times.

capacitance. By using the experiment platform used in this paper, the waveforms of the midpoint voltage with different phase currents are shown in Fig. 8. The switch-on time $T_{\text {give }}$ is $8.3 \mu \mathrm{s}$, and the ideal dead time is approximately $4 \mu \mathrm{s}$. The actual dead time decreases with decreasing phase current. The equivalent capacitance can be calculated with currents and voltages, which are 25,22 , and $13 \mathrm{nF}$ when $i_{p}$ is 0.25 , 0.86, and $4 \mathrm{~A}$, respectively. Therefore, the equivalent capacitance varies with the phase current, and calculating the dead time is difficult because of the inconstant equivalent capacitance.

Based on the experimental tests, the dead times with different phase currents and the given switch-on times are shown in Fig. 9. Fig. 9 shows that the dead time is mainly determined by the phase current and has little relation with the gate signal or bus voltage. However, changes in the dead time is nonlinear, which is hardly expressed by a single expression. By the curve fitting methods, the expression is divided into four parts based on different absolute current values:

$$
\left\{\begin{array}{cc}
T_{d}=0 & 0 \leq\left|i_{p}\right|<0.3 \\
T_{d}=-3.135\left|i_{p}\right|^{2}+6.845\left|i_{p}\right|-1.157 & 0.3 \leq\left|i_{p}\right|<1 \\
T_{d}=-0.09833\left|i_{p}\right|^{2}+0.7457\left|i_{p}\right|+1.943 & 1 \leq\left|i_{p}\right|<5 \\
T_{d}=3.438 & \left|i_{p}\right| \geq 5
\end{array} .\right.
$$

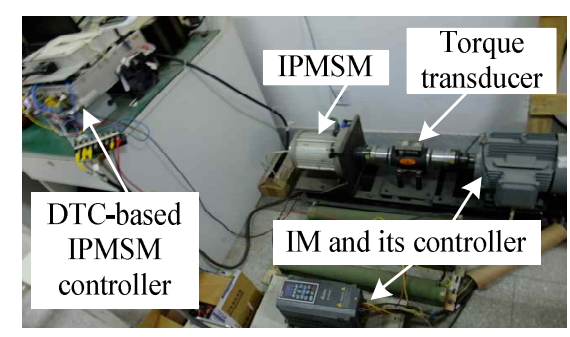

Fig. 10. Experiment platform.

TABLE I

PARAMETERS OF THE PROTOTYPE IPMSM

\begin{tabular}{|c|c|c|}
\hline Number of pole pairs & $P$ & 3 \\
Rotor flux linkage & $\psi_{f}$ & $0.2 \mathrm{~Wb}$ \\
Stator resistance & $R_{s}$ & $1.2 \Omega$ \\
Rated speed & $n_{N}$ & $1000 \mathrm{rpm}$ \\
Rated torque & $T_{N}$ & $10 \mathrm{Nm}$ \\
Bus voltage & $U_{d c}$ & $200 \mathrm{~V}$ \\
\hline
\end{tabular}

The compensation time of the nonlinear dead time is based on the direction and amplitude of the phase current. If $i_{p}>0$, the ON time of the pulse-width modulation adds $T_{d}$, and if $i_{p}$ $<0$, the ON time subtracts $T_{d}$ before issuing.

Given the accuracy limit of current sensors, the direction of a small current is usually difficult to detect. However, by using the experiment platform used in this paper, the direction of the phase current can be ignored if the absolute current value is less than $0.3 \mathrm{~A}$ because the dead time can be neglected. The parasitic capacitance increases the difficulty of dead-time compensation; nevertheless, this parasitic capacitance simplifies the judgment of the zero crossing point of the phase current.

\section{EXPERIMENTAL RESULTS}

\section{A. Experiment Platform}

The experiment platform used in this paper is shown in Fig. 10. This platform contains an IPMSM, an induction motor (IM), and their controllers. A torque-measuring instrument is installed between the axles of the IPMSM and IM to compare the estimated torque with the actual torque. The IM is $5.5 \mathrm{~kW}$ with $1500 \mathrm{rpm}$. The parameters of the IPMSM are listed in Table I.

The proposed DTC is implemented on a Freescale MC56F8346 digital signal processor (DSP), and the control period is $125 \mu \mathrm{s}$. The variables stored in the DSP are observed from the serial port by using the real-time debugging tool FreeMaster. The actual rotor speed and position for observation are obtained from a rotary resolver with 4096 pulses. To simulate the operation of an EV, the IM plays the role of a speed servo, which supplies the variable or constant speed for IPMSM. The IPMSM operates in torque-control mode, and the output energy is absorbed by 

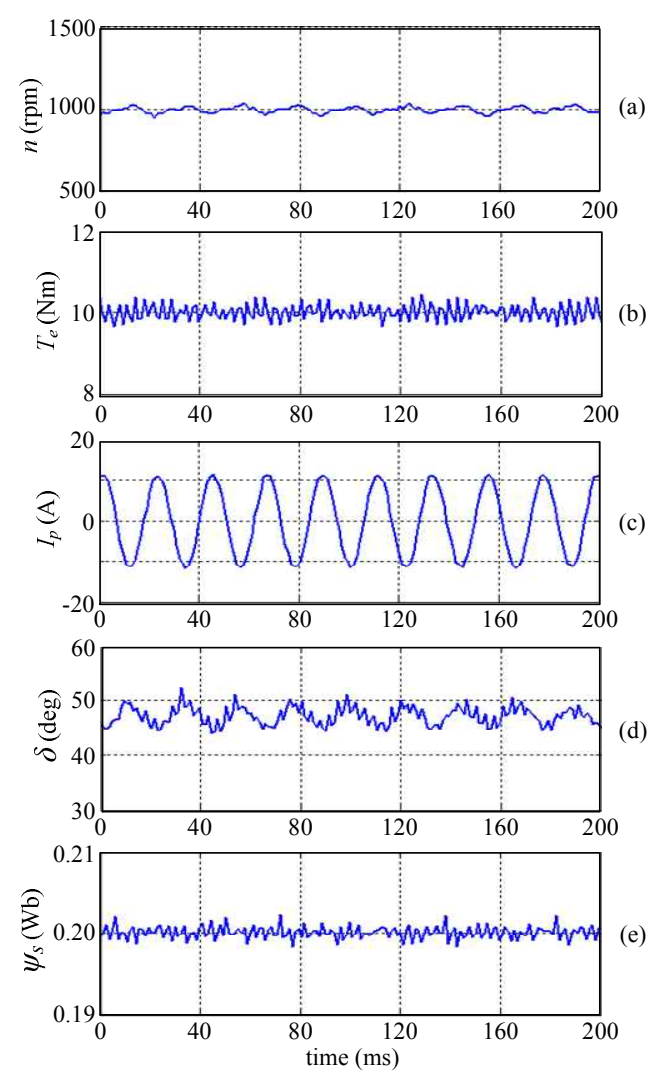

Fig. 11. Steady-state experiment waveforms at $1000 \mathrm{rpm}$ with rated $10 \mathrm{Nm}$. (a) Rotation speed, (b) electromagnetic torque, (c) phase current, (d) torque angle, and (e) stator flux.

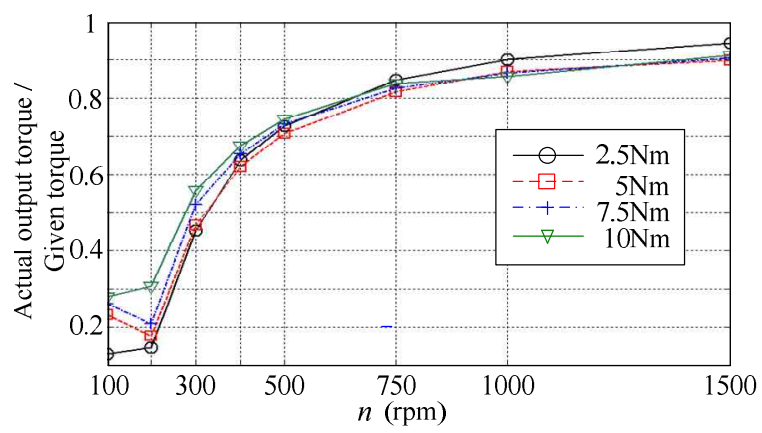

Fig. 12. Torque accuracy of prototype without dead time compensation.

the IM.

In this section, steady and dynamic torque tests are conducted to verify whether the proposed DTC method can meet the torque performance demand of EVs.

\section{B. Steady Torque Performance of the Proposed DTC}

The steady torque performance of the proposed DTC with a rated speed of $1000 \mathrm{rpm}$ and a rated torque of $10 \mathrm{Nm}$ is shown in Fig. 11.

Fig. 11 shows that the electromagnetic torque ripple is approximately $\pm 0.4 \mathrm{Nm}$, and the phase current has a good

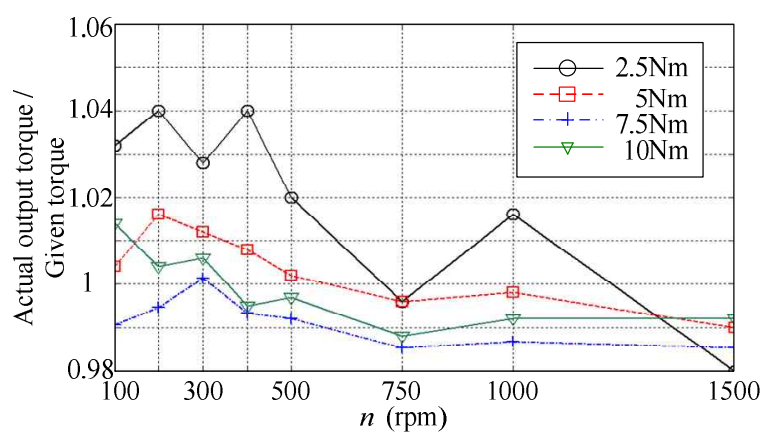

Fig. 13. Torque accuracy of prototype with dead-time compensation.

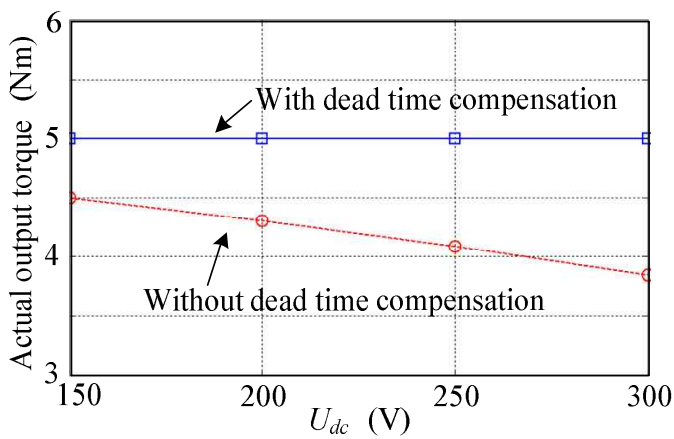

Fig. 14. Torque performance with different bus voltage (given torque is $5 \mathrm{Nm}$ ).

sinusoidal waveform. Torque angle fluctuates around $47^{\circ}$, and stator flux is controlled around $0.2 \mathrm{~Wb}$ with a small ripple.

Torque accuracy is an important part of the steady torque performance. Fig. 12 shows the torque response of different given torques and speeds without dead time compensation. The torque accuracy improves with increasing rotor speed. Torque accuracy is mainly relevant to speed and back electromotive force, and has a small relationship with the value of a given torque. The results show that torque performance is poor and has difficulty in meeting the demands of EV drivers.

By using considering the parasitic capacitances with dead-time compensation, the torque accuracy is shown in Fig. 13. The torque error is less than $5 \%$ and $2 \%$ if the given torque is equal to or less than $10 \mathrm{Nm}$ and if the given torque is equal to or bigger than $5 \mathrm{Nm}$, respectively. Torque accuracy shows great improvement, thus illustrating the validity of the aforementioned dead-time compensation method.

Another evidence of the success of dead-time compensation is that the output torque is invariant with the change of bus voltage. In Fig. 14, the given torque is $5 \mathrm{Nm}$ and the rotor speed is $1000 \mathrm{rpm}$. After applying the dead-time compensation, the actual output torque is nearly constant and is not affected by the bus voltage. 

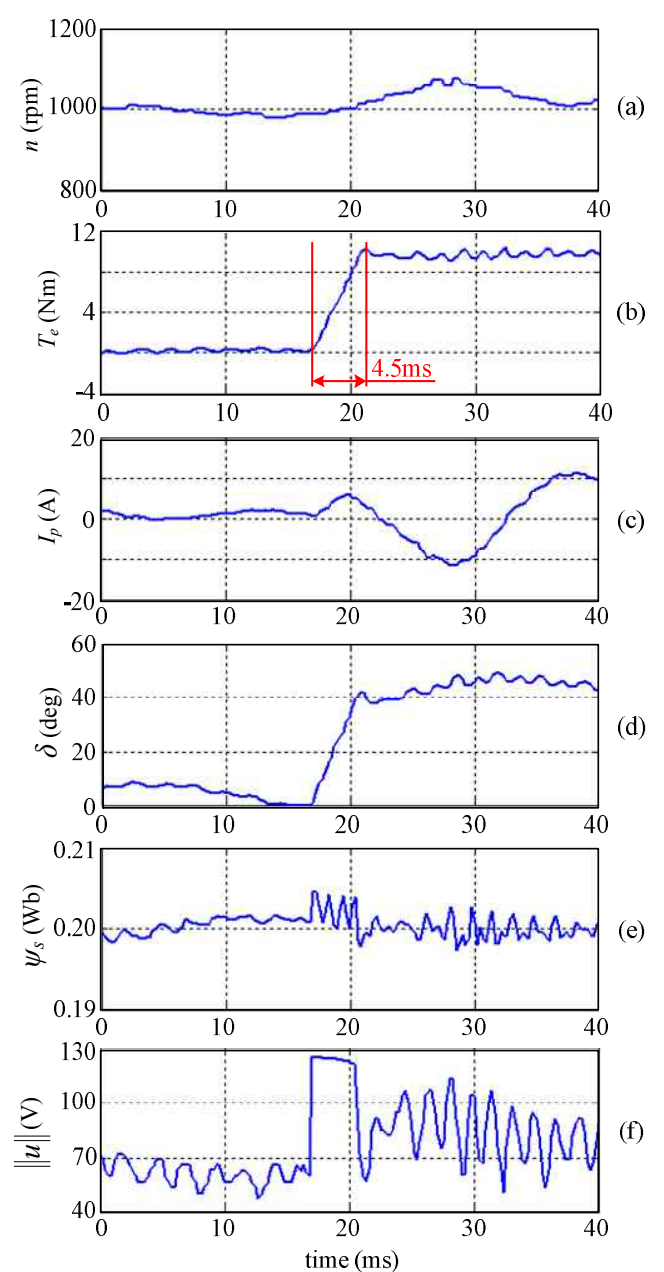

Fig. 15. Experiment waveforms of loading rated $10 \mathrm{Nm}$ suddenly at $1000 \mathrm{rpm}$. (a) Rotation speed, (b) electromagnetic torque, (c) phase current, (d) torque angle, (e) stator flux, and (f) amplitude of output voltage vector.

\section{Dynamic Torque Performance of the Proposed DTC}

The dynamic torque performances of the proposed DTC in a $1000 \mathrm{rpm}$ rated speed are shown in Figs. 15 and 16. In Fig. 15 , the output torque instruction changes from $0 \mathrm{Nm}$ to 10 $\mathrm{Nm}$ at $16 \mathrm{~ms}$. The amplitude of the output voltage vector is regulated immediately. The upsurge duration of the torque is about $4.5 \mathrm{~ms}$, during which motor speed increases transitorily and phase current and torque angle are altered. The stator flux has some small ripples because of the incomplete decoupling.

Compared to loading, the unloading process in Fig. 16 is shorter. The output torque decreases from $10 \mathrm{Nm}$ to 0 within $4 \mathrm{~ms}$. During the time, the output voltage is turned to $0 \mathrm{~V}$; thus, the stator flux obviously decreases, which in turn, accelerates the decrease of the torque. As the output voltage is increasing, the regulation of stator flux is also recovered.

The ability of variable-speed operation is verified in Fig. 17. In the acceleration and deceleration processes between 0
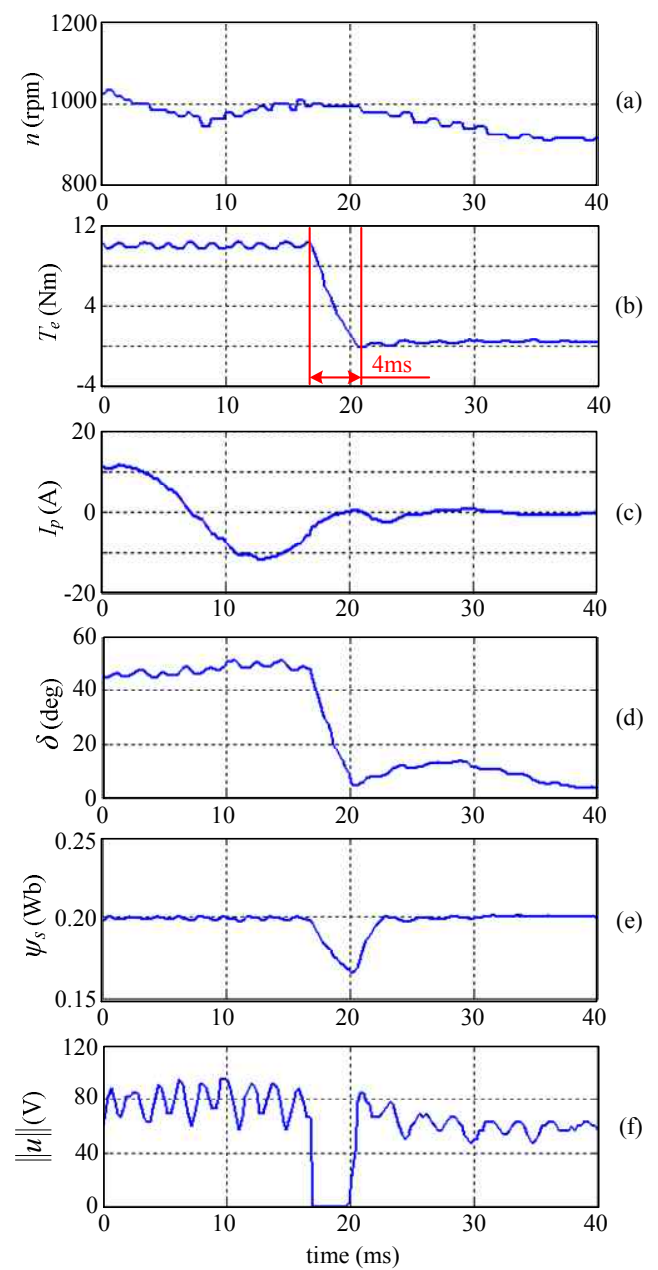

Fig. 16. Experiment waveforms of unloading rated at $10 \mathrm{Nm}$, suddenly at $1000 \mathrm{rpm}$ : (a) Rotate speed, (b) Electromagnetic torque, (c) Phase current, (d) Torque angle, (e) Stator flux, and (f) Amplitude of output voltage vector.

rpm and $1000 \mathrm{rpm}$, the IPMSM can output $10 \mathrm{Nm}$ torque steadily.

\section{CONCLUSIONS}

In this paper, a novel DTC scheme based on the torque angle is introduced for the IPMSMs used in EV drivers. The proposed DTC regulates the torque by rapidly changing the torque angle in the form of polar coordinates. The amplitude and angle of the output voltage vector are determined directly by the PI regulators of torque and stator flux linkage, respectively. Consequently, the proposed DTC scheme retains the advantages of simplification and robustness inherited from conventional DTC schemes and has a fixed switching frequency by the SVPWM. 

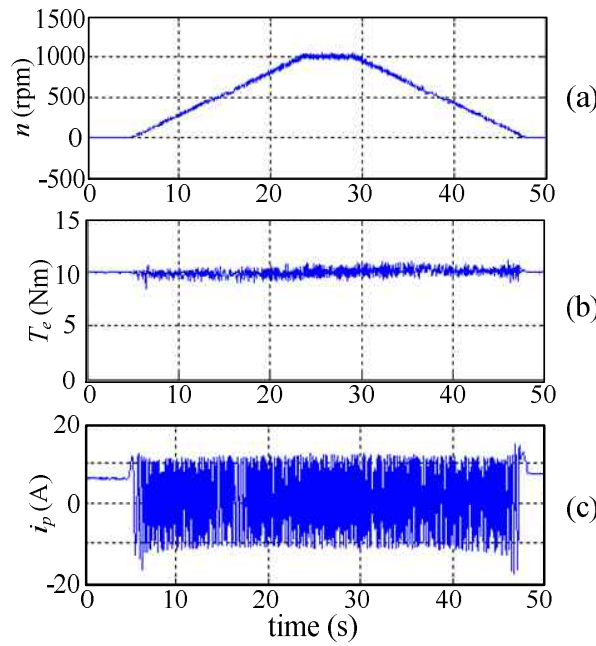

Fig. 17. Variable-speed operation from $0 \mathrm{rpm}$ to $1000 \mathrm{rpm}$ with rated $10 \mathrm{Nm}$ load: (a) Rotation speed, (b) electromagnetic torque, and (c) phase current.

To meet the torque requirement of EV drivers, the torque performance of the proposed DTC scheme is investigated in this study. A nonlinear dead time compensation method that considers the parasitic capacitance is proposed to improve the steady torque performance. The safe operation region of the DTC is restricted by introducing voltage and current limits of both motors and invertors. The proposed DTC has a good steady, dynamic torque performance with a simple structure, which is proven by the experimental results.

\section{ACKNOWLEDGMENT}

This work was supported in part by the National Natural Science Foundation of China (Grant No. 50977045).

\section{REFERENCES}

[1] C. C. Chan and K. T. Chau, "An advanced permanent magnet motor drive system for battery-powered electric vehicles," IEEE Trans. Veh. Tech., Vol. 45, No. 1, pp. 180-189, Feb. 1996.

[2] K. T. Chau, C. C. Chan, and C. Liu, "Overview of permanent magnet brushless drives for electric and hybrid electric vehicles," IEEE Trans. Ind. Electron, Vol. 55, No. 6, pp. 2246-2258, Jun. 2008.

[3] T. D. Batzel and K. Y. Lee, "Electric propulsion with sensorless permanent magnet synchronous motor: implementation and performance," IEEE Trans. Energy. Conv., Vol. 20, No. 3, pp. 575-584, Sep. 2005.

[4] T. Schneider, T. Koch, and A. Binder, "Comparative analysis of limited field weakening capability of surface mounted permanent magnet machines," IEEE Trans. Energy. Conv., Vol. 151, No. 1, pp. 76-82, Jan. 2004.

[5] K.-T. Kim, K.-S. Kim, S.-M. Hwang, T.-J. Kim, and Y.-H. Jung, "Comparison of magnetic forces for IPM and SPM motor with rotor eccentricity," IEEE Trans. Magn., Vol. 37, No. 5, pp. 3448-3451, Sep. 2001.
[6] J.-S. Ko, J.-S. Choi, and D.-H. Chung, "Maximum torque control of an IPMSM drive using an adaptive learning fuzzy-neural network," Journal of Power Electronics, Vol. 12, No. 3, pp. 468-477, May. 2012.

[7] Y.-S. Jung and M.-G. Kim, "Sliding mode observer for sensorless control of IPMSM drives," Journal of Power Electronics, Vol. 9, No. 1, pp. 117-124, Jan. 2009.

[8] M. Hasegawa and K. Matsui, "Position sensorless control for interior permanent magnet synchronous motor using adaptive flux observer with inductance identification," IET Electr. Power Appl., Vol. 3, No. 3, pp. 209-217, May. 2009.

[9] S.-Y. Lee, S.-Y. Kwak, S.-Y. Jung, J.-K. Kim, S.-K. Hong, C.-G. Lee, and H.-K. Jung, "Analysis of inductance characteristics in interior permanent magnet synchronous motor considering inductance variation," in Proc. 12th IEEE Conf. Electromagnetic Field Computation, Florida, 2006, pp. 145.

[10] J.-Y. Lee, S.-H. Lee, G.-H. Lee, J.-P. Hong and J. Hur, "Determination of parameters considering magnetic nonlinearity in an interior permanent magnet synchronous motor," IEEE Trans. Magn., Vol. 42, No. 4, pp. 1303-1307, Apr. 2006.

[11] B. K. Bose and P. M. Szczesny, "A microcomputer-based control and simulation of an advanced IPM synchronous machine drive system for electric vehicle propulsion," IEEE Trans. Ind. Electron., Vol. 35, No. 4, pp. 547-559, Nov. 1998.

[12] M. Bilewski, A. Fratta, L. Giordano, A. Vagati, and F. Villata, "Control of high-performance interior permanent magnet synchronous drives," IEEE Trans. Ind. Appl., Vol. 29, No. 2, pp. 328-338, Mar. 1993.

[13] S. Morimoto, Y. Takeda, K. Hatanaka, Y. Tong, and T. Hirasa, "Design and Control System of Inverter-Driven Permanent Magnet Synchronous Motors for High Torque Operation," IEEE Trans. Ind. Appl., Vol. 29, No. 6, pp. 1150-1155, Nov./Dec. 1993.

[14] M. C. Paicu, I. Boldea, G.-D. Andreescu, and F. Blaabjerg, "Very low speed performance of active flux based sensorless control: interior permanent magnet synchronous motor vector control versus direct torque and flux control," IET Electr. Power Appl., Vol. 3, No. 6, pp. 551-561, May. 2009.

[15] D. Casadei, F. Profumo, G. Serra, and A. Tani, "FOC and DTC: Two viable schemes for induction motors torque control," IEEE Trans. Power Electron., Vol. 17, No. 5, pp. 779-787, Sep. 2002.

[16] G. S. Buja and M. P. Kazmierkowski, "Direct torque control of PWM inverter-fed AC motors-A survey," IEEE Trans. Ind. Electron., Vol. 51, No. 4, pp. 744-758, Aug. 2004.

[17] L. Zhong, M. F. Rahman, W. Y. Hu, K. W. Lim, and M. A. Rahman, "A direct torque controller for permanent magnet synchronous motor drives," IEEE Trans. Energy. Conv., Vol. 14, No. 3, pp. 637-642, Sep. 1999.

[18] L. Tang, L. Zhong, M. F. Rahman, and Y. Hu, “A novel direct torque control for interior permanent-magnet synchronous machine drive with low ripple in torque and flux-A speed-sensorless approach," IEEE Trans. Ind. Appl., Vol. 39, No. 6, pp. 1748-1757, Nov. 2003.

[19] G. H. B. Foo and M. F. Rahman, "Direct torque control of an IPM-synchronous motor drive at very low speed using a sliding-mode stator flux observer," IEEE Trans. Power Electron., Vol. 25, No. 4, pp. 933-943, Apr. 2010.

[20] M. F. Rahman, L. Zhong, Md. E. Haque and M. A. Rahman, "A direct torque-controlled interior permanent-magnet 
synchronous motor drive without a speed sensor," IEEE Trans. Energy. Conv., Vol. 18, No. 1, pp. 17-23, Mar. 2003.

[21] R. Dutta and M. F. Rahman, "A comparative analysis of two test methods of measuring d- and q-axes inductances of interior permanent-magnet machine," IEEE Trans. Magn., Vol. 42, No. 11, pp. 3712-3719, Nov. 2006.

[22] K. M. Rahman and S. Hiti, "Identification of machine parameters of a synchronous motor," IEEE Trans. Ind. Appl., Vol. 41, No. 2, pp. 557-566, Mar. 2005.

[23] Y. Zhang, J. Zhu, Z. Zhao, W. Xu, and D. G. Dorrell, “An improved direct torque control for three-level inverter-fed induction motor sensorless drive," IEEE Trans. Power Electron., Vol. 27, No. 3, pp. 1502-1514, Mar. 2012.

[24] E. Flach, R. Hoffmann, and P. Mutschler, "Direct mean torque control of an induction motor," in Proc. EPE, 1997, Vol. 3, pp. 672-677.

[25] M. Pacas and J. Weber, "Predictive direct torque control for the PM synchronous machine," IEEE Trans. Ind. Electron., Vol. 52, No. 5, pp. 1350-1356, Oct. 2005.

[26] L. Romeral, A. Arias, E. Aldabas, and M. Jayne, "Novel direct torque control (DTC) scheme with fuzzy adaptive torque-ripple reduction," IEEE Trans. Ind. Electron., Vol. 50, No. 3, pp. 487-492, Jun. 2003.

[27] L. Xu and M. Fu, "A novel sensorless control technique for permanent magnet synchronous motors (PMSM) using digital signal processor (DSP)," in Proc. NEACON'97, Dayton, OH, July 14-17, 1997, pp. 403-406.

[28] G.-D. Andreescu, C. I. Pitic, F. Blaabjerg, and I. Boldea, "Combined flux observer with signal injection enhancement for wide speed range sensorless direct torque control of IPMSM drives," IEEE Trans. Energy. Conv., Vol. 23, No. 2, pp. 393-403, Jun. 2008.

[29] Y. Zhang, J. Zhu, W. Xu, and Y. Guo, “A simple method to reduce torque ripple in direct torque-controlled permanent-magnet synchronous motor by using vectors with variable amplitude and angle," IEEE Trans. Ind. Electron., Vol. 58, No. 7, pp. 2848-2860, Jul. 2011.

[30] M. Terashima, T. Ashikaga, T. Mizuno, K. Natori, N. Fujiwara, and M. Yada, "Novel motors and controllers for high-performance electric vehicle with four in-wheel motors," IEEE Trans. Ind. Electron., Vol. 44, No. 1, pp. 28-39, Feb. 1997.

[31] N. Urasaki, T. Senjyu, K. Uezato, and T. Funabashi, "Adaptive dead-time compensation strategy for permanent magnet synchronous motor drive," IEEE Trans. Energy. Conv., Vol. 22, No. 2, pp. 271-281, Jun. 2007.

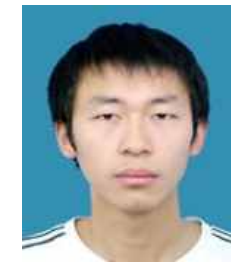

Xin Qiu was born in Huaian, Jiangsu Province, China, in 1985. He received his BE in electrical engineering from Nanjing University of Aeronautics and Astronautics, Nanjing, China, in 2010. He is currently working toward a PhD in the same university. His research interests include high-performance motor drives, permanent-magnet motor design, and electric vehicle drives.

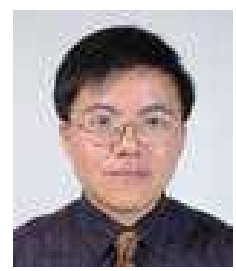

Wenxin Huang was born in Dongtai, Jiangsu Province, China, in 1966. He received his BS degree from the Southeast University, Nanjing, China, in 1988, and $\mathrm{MS}$ and $\mathrm{PhD}$ degrees in electrical engineering from Nanjing University of Aeronautics and Astronautics (NUAA), Nanjing, China, in 1994 and 2002, respectively. In 2003, he joined the faculty of the College of Automation Engineering, NUAA, where he is currently a professor. His research interests include stand-alone power systems, power electronics, and the design and control of electrical machine systems.

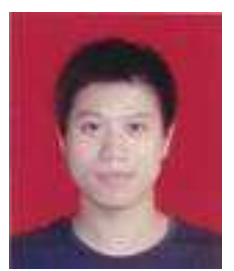

Feifei Bu was born in Maanshan, Anhui Province, China, in 1984. He received his BS in electrical engineering from Anhui University of Technology, Maanshan, China, in 2006. He is currently working toward a $\mathrm{PhD}$ from Nanjing University of Aeronautics and Astronautics, Nanjing, China. His main research interests include stand-alone power systems, wind power systems, and the control and optimal design of generator systems and variable-speed drives. 